DOI: $10.34185 / 1991-7848.2021 .01 .14$

УДК 669.02/09:669:681.3.001.8

Д.М. Тогобицька, Д.О. Степаненко, А.І. Бєлькова, А.П. Петров, Ю.М. Ліхачев ${ }^{14}$

\title{
БАНК ДАНИХ «МЕТАЛУРГІЯ» - ІНФОРМАЦІЙНА ОСНОВА ПРОГНОЗУВАННЯ ВЛАСТИВОСТЕЙ ФІЗИКО-ХІМІЧНИХ СИСТЕМ ТА ÏХ РОЗПЛАВІВ
}

В рамках банку даних «Металургія» створені і постійно розвиваються бази даних «Залізорудні матеріали», «Шлак» $i$ «Феросплави». База даних «Залізорудні матеріали» містить відомості про властивості більще 1200 складів різних видів залізорудної сировини, що включають характеристики міцності $i$ високотемпературні властивості. Описана структура бази експериментальних фізико-хімічних даних про властивості шлакових і оксидних розплавів «Шлак». Розроблено програмні засоби для числової ідентифікації і генерації потрійних діаграм для різних оксидних систем. База даних «Феросплави», включає інформацію про виробництво, хімічний склад і вимоги, що пред'являються до феросплавів різних груп. Дані баз даних використовуються при розробці моделей для прогнозування фізико-хімічних властивостей оксидних і металевих систем, $а$ також в якості вихідних параметрів при математичному, фізико-хімічному та фізичному методах моделювання процесів, що протікають при взаємодії в системі «метал-шлак».

Ключові слова: бази даних, залізорудні матеріали, шлак, діаграми, феросплави, властивості.

В Інституті чорної металургії (ІЧМ) в рамках створеного в кінці минулого століття галузевого Банку даних «Металургія» (БДМет) [1] системно ведуться роботи зі створення баз даних (БД), які надають користувачеві широкий сервіс, що дозволяє не тільки раціонально зберігати необхідні дані, а й зручно оперувати ними. Створені в ІЧМ бази даних, а також моделі для прогнозування фізико-хімічних властивостей вивчених оксидних систем доведені до комп'ютерної реалізації, що робить їх доступними при вирішенні конкретних практичних завдань (оцінки якості залізорудних матеріалів, оптимізації шлакового режиму доменного i сталеплавильного процесів, оцінки технологічних властивостей шлаків і гірських порід при їх використанні в будівельній та інших галузях промисловості та ін.).

Для ведення баз даних розроблена на мові програмування С\# і постійно розвивається інформаційно-пошукова система (IПC), що забезпечує автоматизацію підготовку, введення і коригування даних, пошук і логікосинтаксичний контроль вхідної інформації. Для швидкого доступу до будьякого документу бази автоматично будується індексний файл, який містить

( ) Тогобицька Д.М., Степаненко Д.О., Бєлькова А.І., Петров А.П., Ліхачев Ю.М., 2021 
інформацію про розташування відповідних характеристик в документах. В системі передбачена автоіндексація по текстових полях документу або будьякої їх складової частини відповідно до «маски». Діалогові засоби комплексного перегляду інформації в базі забезпечують її перегляд згідно зі структурою як в обсязі всіх полів бази, так і будь-якого його сегменту по ланцюгу «схема $\rightarrow$ запит $\rightarrow$ документ». Спеціальні програмні засоби забезпечують скануючий пошук інформації з будь-якою вказаною ознакою або їх комбінації і вивантажувати знайдену інформацію в файли Excel.

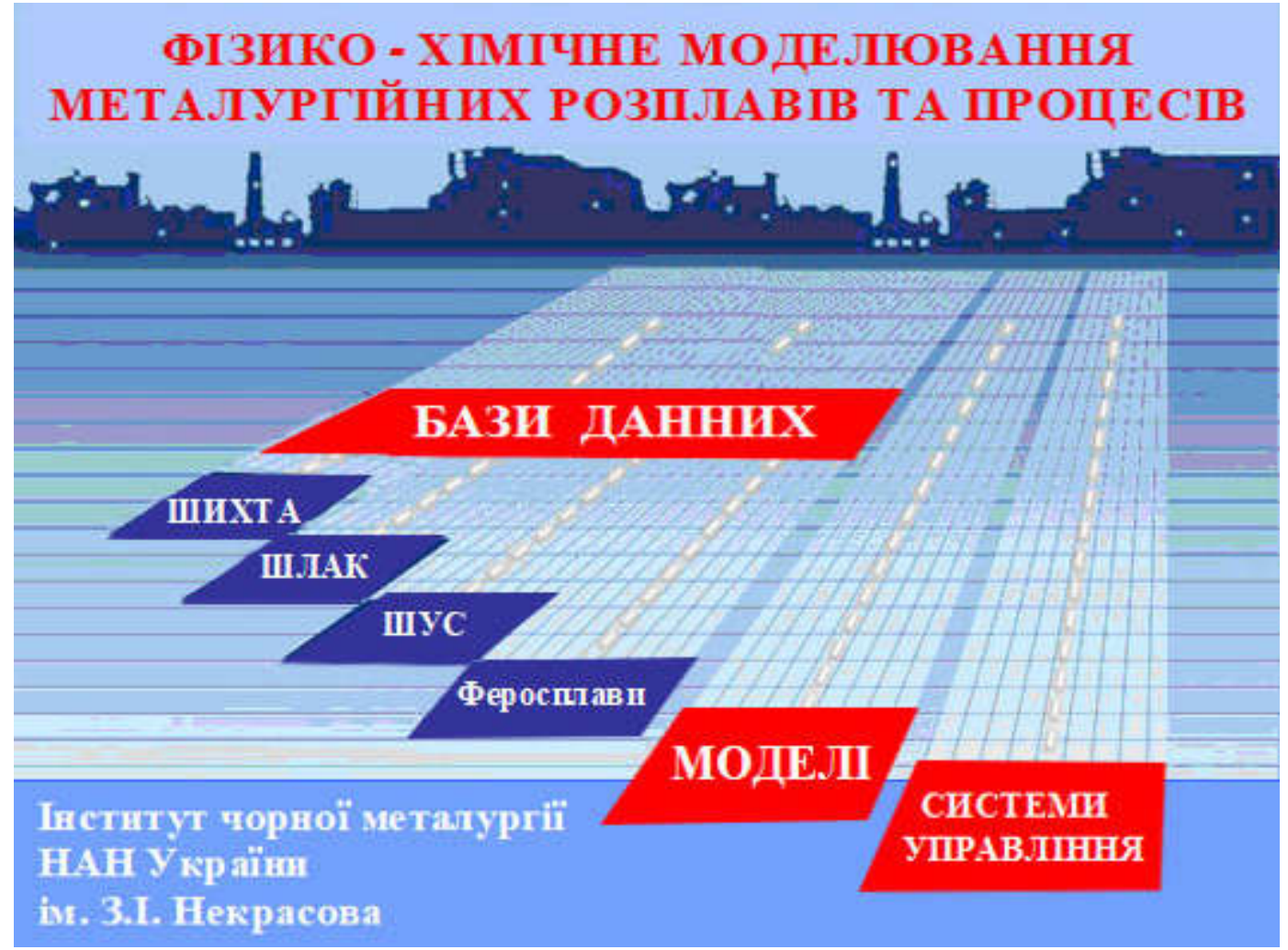

Рисунок 1 - Вхідне вікно у систему БДМет

Бази даних, які містять результати експериментальних досліджень властивостей металургійних розплавів, в тому числі шлаків і інших оксидних систем, служать інформаційною основою для теоретичної та прикладної металургії при розробці шляхів вдосконалення існуючих і принципово нових технологій отримання металопродукції необхідної якості при зниженні витрат на ii виробництво і поліпшення екологічних показників. Найбільший інформаційний потенціал БДМет мають бази даних «Залізорудні матеріали», «Шлак» і створена «Феросплави» (рисунок 1). До теперішнього часу вони найбільш затребувані і активно поповнюються [2-4].

База даних «Залізорудні матеріали» створена на основі накопичених в ІЧМ власних експериментальних даних і літературних публікацій інших авторів (глибина пошуку - 70 років), а також дані довідників, монографій. Згідно 3 розробленим стандартом підготовлено понад 120 паспортів 
експериментальних даних (ПЕД) [1] про властивості більше 1200 складів різних видів залізорудної сировини, що включають характеристики міцності і високотемпературні властивості (температури початку і кінця розм'якшення i плавлення руд, концентратів і агломерату).

Деякі матеріали про плавкість, міцність, відновлюваність представлені у вигляді супутніх експериментальним даним авторизованих моделей, що описують залежності цих властивостей від компонентного хімічного складу. Недолік таких рівнянь полягає в тому, що вони забезпечують достовірність і точність розрахунків тільки в умовах конкретної вибірки складів, використаних для їх висновків, не враховують структуру залізорудних розплавів, і важко виконати аналіз їх фізичного змісту. Значною мірою дискусійний характер висновків аналізу експериментальних даних в подібних випадках обумовлений недосконалістю застосовуваної методології дослідження взаємозв'язку складу багатокомпонентних систем з комплексом їх властивостей.

Створена база даних стала основою для подальшої розробки моделей для вирішення задач прогнозування властивостей залізорудних матеріалів на основі їх хімічного складу 3 використанням фізико-хімічних параметрів міжатомної взаємодії [1]. Відповідно до методики прогнозування властивостей залізорудних матеріалів раніше [5] в ІЧМ були створені моделі для розрахунку металургійних властивостей агломератів і окотишів в залежності від вмісту в них $\mathrm{Fe}_{2} \mathrm{O}_{3}$, FeO i параметрів $\rho$ - кількісний показник катіонів до аніонів i $\Delta \mathrm{e}$ - зарядовий стан системи, що характеризують структуру і властивості шлакової зв'язки системи у вигляді рівнянь: Властивість $=\mathrm{f}\left(\rho, \Delta \mathrm{e}, \mathrm{FeO}, \mathrm{Fe}_{2} \mathrm{O}_{3}\right)$. При цьому були використані лабораторні результати виконані на установках ІЧМ наступних металургійних властивостей агломератів і окотишів всіх фабрик країн СНД: міцність по виходу кондиційної фракції +5 мм (X +5,\%); стираємість по виходу класу 0,5-0 мм $\left(\mathrm{X}_{-0,5}, \%\right)$; ступінь відновлення $\left(\mathrm{R}_{\mathrm{cв}}, \%\right)$ і металізації $\left(\omega_{\mathrm{cв}}, \%\right)$ при $800^{\circ} \mathrm{C}$ (по ГОСТ $\left.19575-84\right)$ і при $1050^{\circ} \mathrm{C}$, просідання шару $(\Delta \mathrm{H}, \%)$, перепад тиску газового потоку $(\Delta \mathrm{P}$, Па) при відновленні шару під навантаженням (по ГОСТ 21707-76).

В результаті актуалізації бази даних «Залізорудні матеріали» новими опублікованими експериментальними даними 3 розширенням діапазонів зміни хімічного складу i властивостей отримані залежності міцності, відновлюваності, просідання шару i перепаду тиску газового потоку агломератів і окотишів від вмісту в них $\mathrm{Fe}_{2} \mathrm{O}_{3}, \mathrm{FeO}$ і інтегральних параметрів $\rho$ i $\Delta$ e, які в окремих випадках носять нелінійний характер (рис. 2). В результаті отримано рівняння для розрахунку властивостей агломератів і окатишів, що використовуються в доменному виробництві на підприємствах України [1]. 
База експериментальних фізико-хімічних даних про властивості шлакових розплавів «Шлак» протягом більше 20 років знаходиться в стадії постійної експлуатації і активного поповнення новими літературними та власними експериментальними даними.
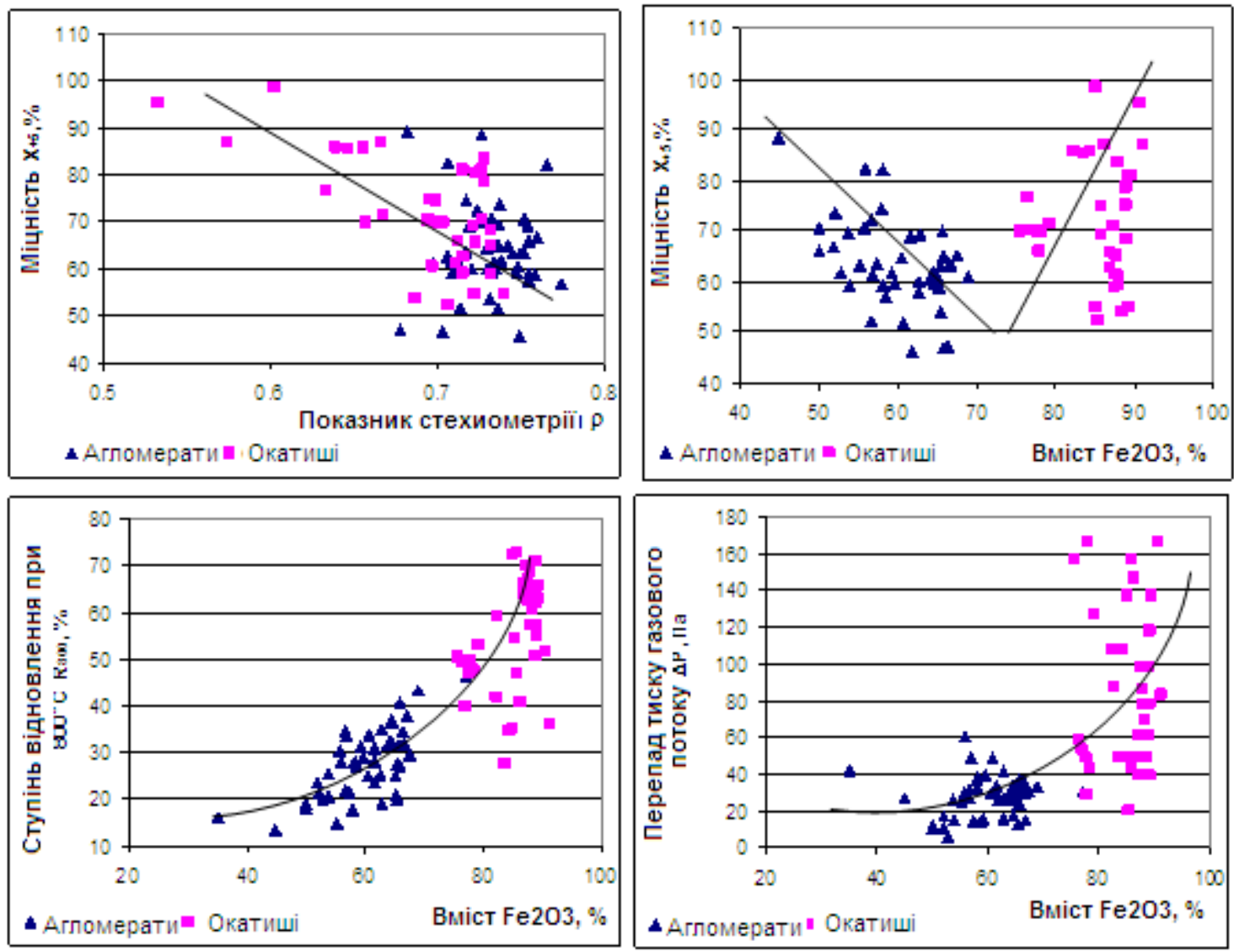

Рисунок 2 - Залежність властивостей агломератів і окотишів від вмісту в них Fe2O3, $\mathrm{FeO}$ і інтегрального параметру $\rho$

В цілому база даних «Шлак» містить інформацію про властивості шлаків різного призначення: доменних, мартенівських, конверторних, рафінувальних для позапічної обробки чавуну i сталі, феросплавного виробництва, для розливання сталі та ін. База даних позбавляє дослідника від необхідності проводити тривалі, трудомісткі і дорогі експерименти, прискорює пошук необхідної інформації, а також дозволяє провести, шляхом обчислювального експерименту, вибір складів оксидних систем з необхідними властивостями в заданому температурному інтервалі. База даних «Шлак» містить інформацію про фазовий, мінералогічний склад і властивості потрійних і четверних систем складу: $\mathrm{CaO}-\mathrm{SiO}_{2}-\mathrm{Al}_{2} \mathrm{O}_{3}-\mathrm{MgO}$ в процесі їх кристалізації (рисунки 3 i 4). Також база поповнена експериментальними даними про в'язкість та електропровідність шлаків процесу електрошлакового переплаву, які були отримані в рамках сумісних наукових досліджень 3 Інститутом електрозварювання ім. Є. О. Патона НАНУ. 
У зв'язку з необхідністю забезпечення наукових досліджень даними про властивості шлакових розплавів різного технологічного призначення, інформаційно-пошукова система бази «Шлак» поповнена програмним забезпеченням*15 (рисунок 5), яке дозволяє виконати числову ідентифікацію трьох- i чотирьох компонентних діаграм фазового стану або зміни властивостей оксидних систем різних за хімічним складом. Принцип роботи програмного забезпечення полягає в завантаженні відповідної, трьох- або чотирьох компонентної потрійної діаграми і знаходженні в полі діаграми необхідної точки з даними про фазовий склад або певних властивостей (температура ліквідус, в'язкість, електропровідність, поверхневий натяг та ін.). В результаті чого виводиться інформація про хімічний склад системи та ㄲï властивості. Програма здатна вирішувати i зворотні завдання, з використанням прогнозних моделей генерувати потрійні діаграми зміни властивостей (рисунок 6).

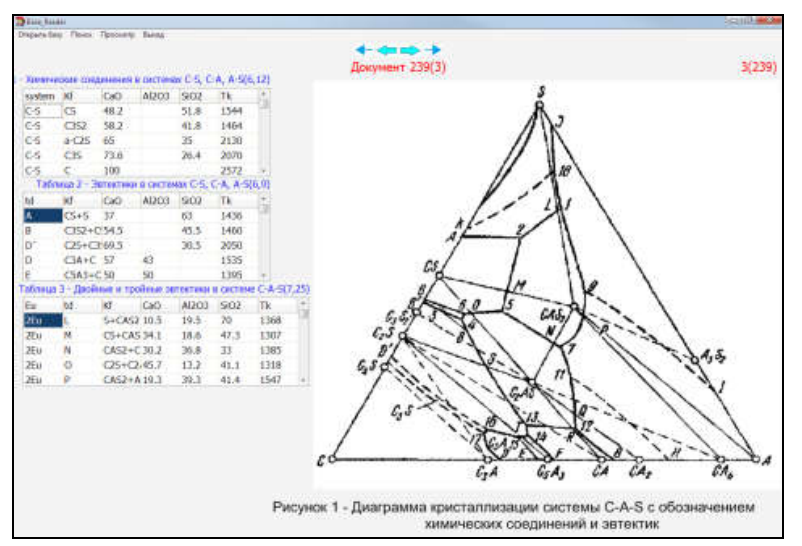

Рисунок 4 - ПЭД бази даних «Шлак» в ІПС, що містить інформацію про фазовий стан системи $\mathrm{CaO}-\mathrm{Al}_{2} \mathrm{O}_{3}-\mathrm{SiO}_{2}$

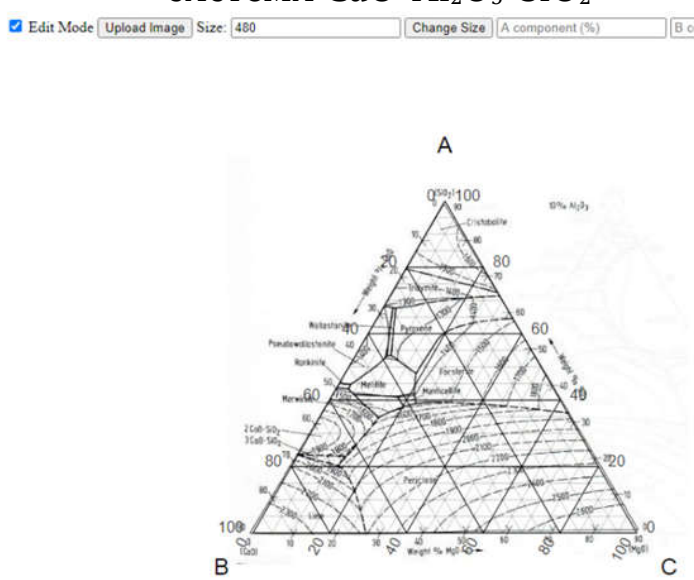

Рисунок 6 - Числова ідентифікація діаграми фазового стану системи $\mathrm{SiO}_{2}-\mathrm{CaO}-$ $\mathrm{MgO}$ з вмістом $10 \% \mathrm{Al}_{2} \mathrm{O}_{3}$

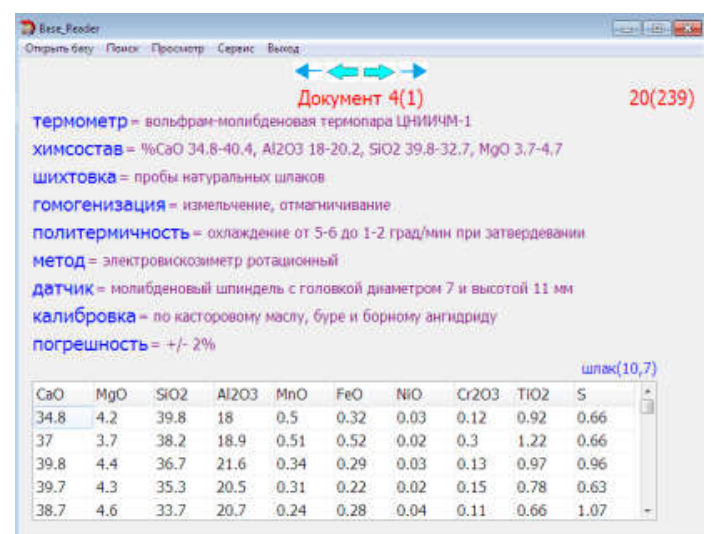

Рисунок 5 - ПЭД бази даних «Шлак» в ІПС, що містить дані про властивості сталеплавильних шлаків

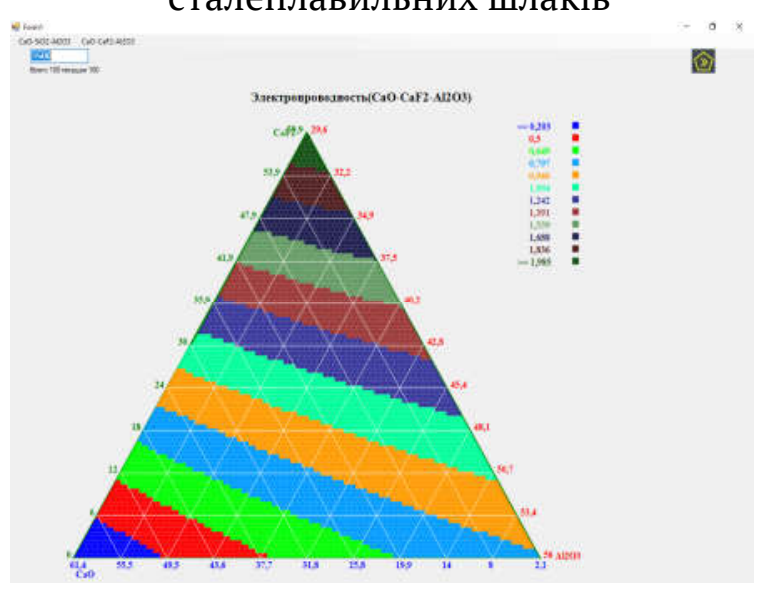

Рисунок 7 - Геннерація потрійної діаграми зміни електропровідності для системи $\mathrm{CaO}-\mathrm{CaF}_{2}-\mathrm{Al}_{2} \mathrm{O}_{3}$

* Програмне забезпечення розроблено інж. І кат. ІЧМ НАНУ С.С. Черським. 
Як показує досвід для обгрунтованого вибору раціонального складу шлаків з позиції забезпечення якості виплавленого металу і оптимізації енергетичних витрат на його виплавку для конкретних технологічних умов роботи металургійного агрегату необхідно враховувати структурний і фазовий стан шлакового розплаву [6].

База даних «Феросплави» містить інформацію вітчизняних і зарубіжних авторів про виробництво, хімічний склад і вимоги, що пред'являються до феросплавів різних груп. В даний час в базу даних введено 35 ПЕД, що містять інформацію (понад 200 складів) про комплекс фізико-хімічних, фізичних i теплофізичних властивостей феросплавів широкого сортаменту: ферохрому, феросиліцію, феромарганцю, ферованадію, феротитану, фероніобію, феронікелю, фероцирконію, феромолібдену, силікокальцію, силікомарганцю та ін. Інформація про найважливіші теплофізичні, фізико-хімічні і фізикомеханічні властивості систематизована і прив'язана до конкретного хімічного складу даної марки феросплавів.

Зокрема, в роботі [7] запропоновано рівняння для оцінки фізичних, фізико-хімічних i теплофізичних властивостей (ентальпія, щільність, температура плавлення, теплоємність, теплота плавлення, коефіцієнт теплопровідності, коефіцієнт температуропровідності, питомий електроопір) феросплавів промислових марок, наявні експериментальні дані по яким обмежені або носять суперечливий характер. Розроблено напівемпіричні моделі, що дозволяють прогнозувати вплив зміни складу, вираженого через інтегральні параметри міжатомної взаємодії, на властивості стандартних марок феросплавів різних груп [8]:

а) хромисті феросплави (високо-, середньо- i низьковуглецевий ферохром);

б)марганцеві феросплави (високо-, середньо- і низьковуглецевий феромарганець), феросилікомарганець, марганець металевий;

в) сплави кремнію (феросиліцій всіх марок);

г) ферованадій, фероніобій, феробор, феротитан, феронікель.

Наявність баз даних і моделей по кожному переділу виробництва металопродукції дозволяє оперативно генерувати інструментальні засоби (підсистеми) для комплексного аналізу, прогнозування та оптимізації фізикохімічних процесів; техніко-економічних показників технологій отримання металу (продуктивності, енергетичних i сировинних витрат), а також наскрізного аналізу процесів отримання високоякісної продукції на всіх переділах, аудиту підприємств і галузі в цілому за рахунок залучення сучасних досягнень академічної і галузевої науки. 


\section{ЛІТЕРАТУРА}

1. Приходько Э. В. Прогнозирование физико-химических свойств оксидных систем / Э. В. Приходько, Д. Н. Тогобицкая, А. Ф. Хамхотько, Д. А. Степаненко // Днепропетровск: Пороги, 2013. - 344c.

2. От баз данных к базам знаний о свойствах металлургических шлаков /Тогобицкая Д.Н., Хамхотько А. Ф., Белькова А. И. [и др.] //Сб. н. т. ИЧМ «Фундаментальные и прикладные проблемы черной металлургии». - Днепропетровск. - Вып. 9. - 2004. - С. 168-175.

3. Использование базы вискозиметрических данных для расчета кристаллизационной способности металлургических шлаков / [Тогобицкая Д. Н. , Хамхотько А. Ф., Лихачев Ю. М. [и др.] //Сб. н. т. ИЧМ «Фундаментальные и прикладные проблемы черной металлургии». Днепропетровск. - Вып.18. - 2008. - С. 200-209.

4. Інформаційно-аналітична система для дослідження кристалізаційної здатності металургійних шлаків / Д.М. Тогобицька, Д.О. Степаненко, А.Ф. Хамхотько А. Ф. [та ін.] //Системні технології. Регіональний міжвузівський збірник наукових праць. Дніпропетровськ. - Випуск 2(67). - 2010. - С. 74-80.

5. Тогобицкая Д.Н. Информационное обеспечение и прогноз свойств железорудных материалов / Д.Н. Тогобицкая, А.Ф. Хамхотько, Л.А. Головко // Фундаментальные и прикладные проблемы черной металлургии. - Вып. 2. - Киев: Наукова думка. -1998. - С. 93-100.

6. Степаненко Д. А. К обоснованию выбора рационального шлакового режима в металлургических процессах / Д. А. Степаненко, О. Волкова, Х.-П. Хеллер, П. И. Оторвин, Д. А. Чебыкин // Сталь, №9, 2017. - с. 2 - 5.

7. Тогобицкая Д.Н. База данных и модели для экспертной оценки эффективности использования ферросплавов при производстве стали / Д.Н. Тогобицкая, В.П. Пиптюк, А.Ф. Петров, С. В. Греков, И.Р. Снигура, Ю.М. Лихачев, Л. А. Головко // Сб.н.тр. ИЧМ «Фундаментальные и прикладные проблемы черной металлургии». - Днепропетровск. 2017. - Вып. 31. - C.150-165.

8. Togobitskaya D.N. Prediction of Ferroalloy Properties for Expert Evaluation of the Efficiency of their Use During Addition to Steel in a Ladle Furnace Unit / Togobitskaya D.N., Piptyuk V.P., Petrov A.F., Grekov E.V., Mirgorodskaya A.S. // Metallurgist. - 2019. Vol 62. No (11-12). pp. 1115-1122.

\section{REFERENCES}

1. Prihodko E. V. Prognozirovanie fiziko-himicheskih svoystv oksidnyih sistem / E. V. Prihodko, D. N. Togobitskaya, A. F. Hamhotko, D. A. Stepanenko // Dnepropetrovsk: Porogi, 2013. - 344 p.

2. Ot baz dannyih $\mathrm{k}$ bazam znaniy o svoystvah metallurgicheskih shlakov /Togobitskaya D.N., Hamhotko A. F., Belkova A. I. [i dr.] //Sb. n. t. IChM «Fundamentalnyie i prikladnyie problemyi chernoy metallurgii». - Dnepropetrovsk. - Vyip. 9. - 2004. - P. 168-175.

3. Ispolzovanie bazyi viskozimetricheskih dannyih dlya rascheta kristallizatsionnoy sposobnosti metallurgicheskih shlakov / [Togobitskaya D. N. , Hamhotko A. F., Lihachev Yu. M. [i dr.] //Sb. n. t. IChM «Fundamentalnyie i prikladnyie problemyi chernoy metallurgii». - Dnepropetrovsk. Vyip.18. - 2008. - P. 200-209.

4. InformatsIyno-analItichna sistema dlya doslIdzhennya kristalIzatsIynoYi zdatnostI metalurgIynih shlakIv / D.M. Togobitska, D.O. Stepanenko, A.F. Hamhotko A. F. [ta In.] //SistemnI tehnologIYi. RegIonalniy mIzhvuzIvskiy zbIrnik naukovih prats. - DnIpropetrovsk. Vipusk 2(67). - 2010. - P. 74-80.

5. Togobitskaya D.N. Informatsionnoe obespechenie i prognoz svoystv zhelezorud-nyih materialov / D.N. Togobitskaya, A.F. Hamhotko, L.A. Golovko // Fundamentalnyie i prikladnyie problemyi chernoy metallurgii. - Vyip. 2. - Kiev: Naukova dumka. -1998. - P. 93-100.

6. Stepanenko D. A. K obosnovaniyu vyibora ratsionalnogo shlakovogo rezhima v metallurgicheskih protsessah / D. A. Stepanenko, O. Volkova, H.-P. Heller, P. I. Otorvin, D. A. Chebyikin // Stal, \#9, 2017. - c. $2-5$. 
7. Togobitskaya D.N. Baza dannyih modeli dlya ekspertnoy otsenki effektivnosti ispolzovaniya ferrosplavov pri proizvodstve stali / D.N. Togobitskaya, V.P. Piptyuk, A.F. Petrov, S. V. Grekov, I.R. Snigura, Yu.M. Lihachev, L. A. Golovko // Sb.n.tr. IChM «Fundamentalnyie i prikladnyie problemyi chernoy metallurgii». - Dnepropetrovsk. - 2017. - Vyip. 31. - S.150-165.

8. Togobitskaya D.N. Prediction of Ferroalloy Properties for Expert Evaluation of the Efficiency of their Use During Addition to Steel in a Ladle Furnace Unit / Togobitskaya D.N., Piptyuk V.P., Petrov A.F., Grekov E.V., Mirgorodskaya A.S. // Metallurgist. - 2019. Vol 62. No (11-12). pp. 1115-1122.

Received 05.01.2021. Accepted 20.01.2021.

UDK 669.02/09:669:681.3.001.8

D.N. Togobitskaya, D.A. Stepanenko, A.I. Bel'kova, A.F. Petrov, Y.M. Lihachov

\section{DATABANK "METALLURGY" - AN INFORMATION BASIS FOR PREDICTING THE PROPERTIES OF PHYSICAL AND CHEMICAL SYSTEMS AND THEIR MELTS}

The Metallurgy data bank has been created at the Institute of Ferrous Metallurgy, systematic work is underway to create and develop an integrated knowledge base for end-toend analysis of metal production based on modern information computer technologies. The greatest information capacity is possessed by databases on the properties of iron ore materials (database "Iron ore materials") and slag melts (database "Slag"), which are most in demand and are actively replenished. The "Iron ore materials" database contains information on the properties of more than 1200 compositions of various types of iron ore raw materials, including strength characteristics and high-temperature properties. The database "Slag" contains more than 500 documents containing information on the properties of more than 8000 compositions of slags and oxides for various purposes. The "Ferroalloys" database includes information from domestic and foreign authors on production, chemical composition and requirements for ferroalloys of various groups. At present, 35 passports have been entered into the database, which contain information (more than 200 compositions) about a complex of physicochemical, physical and thermophysical ferroalloys of a wide range: ferrochrome, ferrosilicon, ferromanganese, ferrovanadium, ferrotitanium, ferroniobium, ferronickel, ferrozirconium, ferromolybdenum , silicomanganese, etc. The presence in the Metallurgy data bank of databases and models for each redistribution of metal production allows you to quickly generate tools (subsystems) for complex analysis, forecasting and optimization of physical and chemical processes; technical and economic indicators of metal production technologies, as well as end-to-end analysis of the processes of obtaining high-quality products, audit of enterprises and the industry as a whole by attracting modern scientific achievements.

Keywords: databases, iron ore materials, slag, diagrams, ferroalloys, properties.

Тогобищька Дар'я Миколаївна - д.т.н., професор, зав. відділом фізико-хімічних проблем металургійних процесів, Інститут чорної металургії ім. 3.І. Некрасова НАНУ.

Степаненко Дмитро Олександрович - к.т.н., старший науковий співробітник відділу фізико-хімічних проблем металургійних процесів, Інститут чорної металургії ім. 3.I. Некрасова НАНУ. 
Бєлькова Алла Іванівна - к.т.н., старший науковий співробітник відділу фізикохімічних проблем металургійних процесів, Інститут чорної металургії ім. 3.I. Некрасова НАН України.

Петров Олександр Пилипович - науковий співробітник відділу фізико-хімічних проблем металургійних процесів, Інститут чорної металургії ім. 3.І. Некрасова НАНУ.

Ліхачов Юрій Михайлович - науковий співробітник відділу фізико-хімічних проблем металургійних процесів, Інститут чорної металургії ім. 3.І. Некрасова НАНУ.

Тогобищкая Дарья Николаевна - д.т.н., профессор, зав. отделом физико-химических проблем металлургических процессов, Институт черной металлургии им. З.И. Некрасова НАНУ.

Степаненко Дмитрий Александрович - к.т.н., старший научный сотрудник отдела физико-химических проблем металлургических процессов, Институт черной металлургии им. 3. И. Некрасова НАНУ.

Белькова Алла Ивановна - к.т.н., старший научный сотрудник отдела физикохимических проблем металлургических процессов, Институт черной металлургии им. З. И. Некрасова НАНУ.

Петров Александр Филиппович - научный сотрудник отдела физико-химических проблем металлургических процессов, Институт черной металлургии им. З. И. Некрасова НАНУ.

Лихачев Юрий Михайлович - научный сотрудник отдела физико-химических проблем металлургических процессов, Институт черной металлургии им. 3. И. Некрасова НАН Украины.

Togobitskaya Daria - Doctor of Technical Sciences Professor, Head of the Department of Physical and Chemical Problems of Metallurgical Processes, Z. I. Nekrasov Iron \& Steel Institute of NAS of Ukraine.

Stepanenko Dmytro - PhD, Senior Researcher Department of Physical and Chemical Problems of Metallurgical Processes, Z. I. Nekrasov Iron \& Steel Institute of NAS of Ukraine.

Bel'kova Alla - PhD, Senior Researcher Department of Physical and Chemical Problems of Metallurgical Processes, Z. I. Nekrasov Iron \& Steel Institute of NAS of Ukraine.

Petrov Aleksandr - Researcher Department of Physical and Chemical Problems of Metallurgical Processes, Z. I. Nekrasov Iron \& Steel Institute of NAS of Ukraine.

Lihachov Yurii - Researcher Department of Physical and Chemical Problems of Metallurgical Processes, Institute of Ferrous Metallurgy named after Z.I. Nekrasov NAS of Ukraine. 